\title{
PERFIL DE SABOR DO CAFÉ CONILON OBTIDO POR DIFERENTES FORMAS DE MANEJO
}

\author{
A. C. Z. VENTURIN ${ }^{1}$, L.S.ARRIECHE ${ }^{2 *}$ \\ ${ }^{1}$ Aluna de Engenharia Química, participante do PIVIC/PIIC 2013-2014, Universidade Federal \\ do Espírito Santo, Centro Universitário Norte do Espírito Santo \\ ${ }^{2}$ Orientador, Universidade Federal do Espírito Santo, Centro Universitário Norte do Espírito \\ Santo, Departamento de Engenharias e Tecnologia \\ E-mail para contato: leonardo.arrieche@ufes.br
}

\begin{abstract}
RESUMO - O café Conilon é um dos principais produtos agrícolas brasileiros, sendo fonte de renda de boa parte da população do país. A qualidade é um dos fatores que mais agrega valor ao grão, portanto, buscou-se avaliar através da análise sensorial as técnicas de manejo e processamento que atribuem melhores características ao café Conilon. Foi realizada a seleção da equipe de provadores através dos testes triangular, comparação pareada e ordenação. Os dados obtidos foram tratados estatisticamente segundo normas da ABNT e nível de significância de $5 \%$. Os participantes com $80 \%$ ou mais de acertos foram selecionados. A equipe realizou a análise sensorial de amostras de diferentes lavouras da região, visando obter o grau de aceitação com a escala hedônica e o perfil de sabor. Os resultados foram analisados estatisticamente e dispostos em gráficos aranha. As análises foram conclusivas quanto à interferência do manejo e processamento do café Conilon na qualidade do produto final, bem como na aceitação do consumidor. $\mathrm{O}$ estudo foi importante para avaliar as técnicas utilizadas pelos produtores e pode ser empregado no aumento da qualidade e lucratividade nas lavouras.
\end{abstract}

\section{INTRODUÇÃO}

Existem várias espécies de café, sendo as mais conhecidas no mundo as classes Coffea arabica (café Arábica) e Coffea canephora (café Robusta ou Conilon). A qualidade apresenta-se como parâmetro fundamental para a valorização do café robusta e está diretamente relacionada à condução adequada da produção após a colheita e aos diferentes graus de torra (Morais et al., 2009).

$\mathrm{Na}$ colheita, os frutos devem estar em seu ponto máximo de maturação, e serem colhidos sem que entrem em contato com a terra, para que não se contaminem com microrganismos. Após a colheita, devem passar pela pré-limpeza, retirando as impurezas vindas do campo como folhas e paus, e lavados o mais rápido possível, com o objetivo de retirar a poeira e separar os frutos de acordo com as fases de maturação, que são: cereja, verde e seco. Na fase de pós-colheita, os grãos podem ser processados de duas formas: via seca ou via úmida. Na via seca, são obtidos cafés naturais, onde a secagem do fruto é feita com casca, polpa, mucilagem, pergaminho e sementes. Por via úmida, o café é despolpado, descascado e desmucilado, originando cafés de melhor qualidade, por diminuir o ataque de microrganismos 
causadores de fermentações indesejáveis, que resultam em bebidas inferiores. Depois de lavado, o café é seco ao sol ou em secadores de convecção forçada com o ar aquecido artificialmente. Após secagem completa, o café passará pela fase de beneficiamento, onde será retirada a casca, e por um beneficiamento adicional, onde serão retirados grãos verdes, pretos, defeituosos, ardidos e brocados (Bartholo et al., 1989).

Uma das formas de se avaliar a qualidade dos grãos após o manejo e processamento é através da análise sensorial, que é uma ciência relativamente nova. Esta disciplina cresceu rapidamente na segunda metade do século XX, juntamente com a expansão de alimentos processados (Lawless e Heymann, 2010). É definida como um método científico usado para medir, analisar e interpretar as respostas obtidas através dos sentidos da visão, olfato, tato, paladar e audição (Amerine, 1965). Pode ser empregada no desenvolvimento de novos produtos, reformulação de produtos já existentes e dentre outras aplicações, na identificação das preferências dos consumidores por determinados produtos ou aspectos dos produtos. Com esta técnica de análise, é possível avaliar as variações na condução da produção, após a colheita, em diferentes amostras e obter o grau de aceitação dos consumidores com os aspectos encontrados no produto final, em especial o sabor, como critérios de avaliação.

\section{METODOLOGIA}

\subsection{Seleção da Equipe de Provadores}

A fim de selecionar a equipe de provadores, foram realizados três testes de análise sensorial, sendo os dados analisados estatisticamente segundo as normas da ABNT. As amostras foram preparadas de forma padronizada, com o mesmo tipo de água mineral, com $\mathrm{pH}$ pouco abaixo de 7 , temperatura de operação de aproximadamente $92^{\circ} \mathrm{C}$, mesmo tipo de filtro, convencional para granulometria fina e mesma quantidade de pó de café e açúcar (levemente adocicado).

O teste triangular consiste basicamente na apresentação de três amostras simultaneamente aos provadores, duas delas idênticas. A tarefa é identificar qual amostra se distingue das demais que, neste caso, duas pertenciam ao mesmo lote de fabricação. As amostras são codificadas aleatoriamente e a probabilidade de se selecionar a amostra correta por acaso é de 1/3. Em uma série de $\mathrm{N}$ julgamentos independentes, a probabilidade de respostas corretas por acaso pode ser determinada, e caso inferior a 10\%, pode-se concluir que o analista obteve diferença real na qualidade sensorial (Chaves e Sproesser, 1996).

O teste de comparação pareada é utilizado quando se deseja colocar um produto em competição direta com outro. As amostras de cafés com qualidades distintas foram codificadas de forma aleatória e o provador impelido a escolher uma em detrimento da outra, havendo 50\% de probabilidade de acerto (Chaves e Sproesser, 1996).

Por fim, o teste de ordenação consiste na apresentação de três ou mais amostras de maneira casual e balanceada, onde os julgadores são solicitados a ordená-las, seja em ordem crescente ou decrescente, quanto à intensidade de um determinado atributo. $\mathrm{O}$ resultado é obtido pela soma das ordens obtidas dos julgadores a cada uma das amostras. Se a diferença entre as somas das ordens for maior ou igual ao valor tabelado, conclui-se que existe diferença significativa entre as amostras, ao nível de significância correspondente (Chaves e 


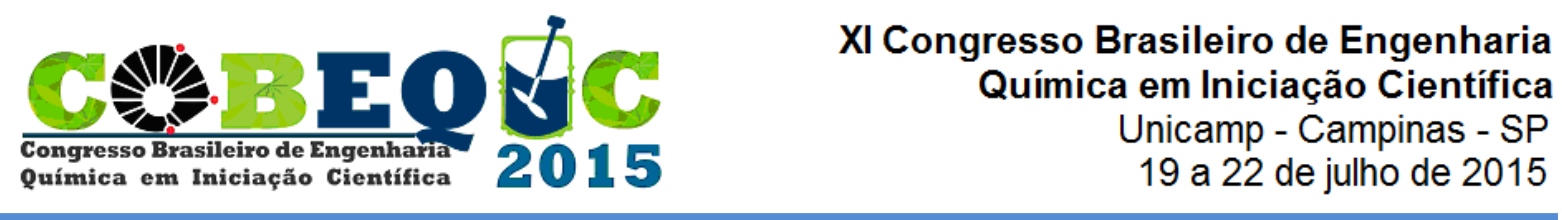

Sproesser, 1996). Cada provador recebeu quatro amostras de café Arábica com diferentes porcentagens de café Conilon e as ordenou de forma crescente de sabor amargo.

\subsection{Testes Sensoriais Descritivos}

Para os testes descritivos, foram utilizadas 7 amostras de café Conilon, produzidas em municípios da região Norte do Espírito Santo. Tais amostras foram cedidas pela Cooperativa Agrária dos Cafeicultores de São Gabriel (COOABRIEL) e suas características estão dispostas na Tabela 1.

Tabela 1. Amostras selecionadas para os testes descritivos e suas características.

\begin{tabular}{ccccc}
\hline Amostra & Café & Tipo & Secagem & Temperatura \\
\hline 01 & Natural Verde & Bica corrida & Fogo indireto & $250{ }^{\circ} \mathrm{C}$ \\
02 & Cereja descascado & Bica corrida & Terreiro coberto & $40{ }^{\circ} \mathrm{C}$ \\
& $\begin{array}{c}\text { (coleta seletiva) } \\
\text { Natural }\end{array}$ & Bica corrida & Fogo direto & $200{ }^{\circ} \mathrm{C}$ \\
03 & Natural & Bica corrida & Terreiro de terra & Ambiente \\
04 & Natural verde & Bica corrida & Fogo direto & $300{ }^{\circ} \mathrm{C}$ \\
05 & Natural & Bica corrida & Terreiro coberto & $40{ }^{\circ} \mathrm{C}$ \\
06 & Cereja Descascado & Bica corrida & Fogo indireto & $150{ }^{\circ} \mathrm{C}$ \\
07 & & &
\end{tabular}

Fonte: Os autores.

Foi realizado o teste de aceitação através da escala hedônica, no qual o indivíduo expressa o grau de gostar ou de desgostar de um determinado produto. A escala utilizada foi a de 9 pontos em escala decrescente, que contém os termos (9) gostei extremamente; (8) gostei muito; (7) gostei moderadamente; (6) gostei ligeiramente; (5) indiferente; (4) desgostei ligeiramente; (3) desgostei moderadamente; (2) desgostei muito e (1) desgostei extremamente (Lawless e Heymann, 2010). As amostras foram codificadas com algarismos de três dígitos aleatórios e apresentadas a 15 dos julgadores treinados para que avaliassem o quanto gostam ou desgostam. Foram testadas 7 amostras e os dados foram avaliados estatisticamente pela a análise da variância e comparação das médias de pares de amostras pelo teste de Tukey. $\mathrm{O}$ segundo teste realizado foi o de Perfil de Sabor, onde para cada amostra, o julgador avalia as características sensoriais percebidas e suas intensidades. Estas características foram escolhidas de forma consensual pelos julgadores treinados. Os resultados foram dispostos e analisados em forma de gráfico aranha e posteriormente relacionados com o teste de aceitação.

\section{RESULTADOS E DISCUSSÕES}

\subsection{Seleção Da Equipe}

Os candidatos com qualidades sensoriais mais apropriadas foram selecionados a partir dos dados obitidos. No teste triangular, dos 28 candidatos, 23 escolheram a amostra "B", 2 escolheram a " $A$ " e 3 escolheram " $A$ " " como sendo a diferente. As amostras " $A$ " e " $A$ " " são 
do mesmo lote de fabricação, idênticas. Já a amostra "B" é de um lote diferente. Com os resultados e de acordo com a Associação Brasileira de Normas Técnicas (ABNT), 1993b, com $5 \%$ de significância e número de provadores igual a 28 , esperam-se uma quantidade mínima de 15 respostas corretas para existir diferenças entre as amostras. Como o número de pessoas que escolheram a amostra "B" foi maior que o mínimo esperado, pode se concluir que esta apresenta diferenças significativas em relação às demais.

Na Comparação Pareada, a amostra "A" possuía melhor qualidade que "B". Esta qualidade é alcançada por diversos fatores como tipo de grãos utilizados, região onde são plantados e forma de processamento durante e após a colheita. Com os resultados e seguindo as normas da Associação Brasileira de Normas Técnicas (ABNT), 1993b, para o número de 28 provadores e $5 \%$ de significância é necessário que se tenha 20 respostas para estabelecer uma diferença significativa. O número de participantes que selecionaram a amostra " $A$ " foi 21 , indicando que esta é a mais preferida, como esperado.

As amostras A, B, C e D são amostras de café arábica com diferentes porcentagens de café Conilon misturadas, sendo " $A$ " café Arábica puro, "B" 40\% Conilon, "C" $15 \%$ Conilon e "D" 65\% Conilon. A partir das diferenças entre os somatórios e segundo Lawless e Heymann (2010), para 5\% de significância e 28 julgadores, a diferença entre as somas deveria ser igual ou superior a 25. O somatório de pontos das amostras "A", "B", "C" e " $D$ " foram, respectivamente, 101, 59, 77 e 42. Fazendo as diferenças entre "A" e "B", " $A$ " e " $C$ ", " $A$ " e "D", "B" e "C", "B" e "D", e "C" e "D", obteve-se, respectivamente, os valores de 42, 24, 59, 18,17 e 35 . Isso mostra que, não há diferença significativa entre as amostras " $A$ " e "C $C$ ", " $B$ " e "C", e "B" e "D", tendo as outras apresentado diferença significativa.

Dos 28 participantes, 20 alcançaram um desempenho maior ou igual a $80 \%$ de acerto, ou seja, $71,42 \%$ dos provadores. Mesmo não havendo diferença significativa entre algumas amostras, a seleção da equipe foi satisfatória já que os participantes concordaram na maioria de suas respostas.

\subsection{Testes Sensoriais Descritivos}

Os resultados obtidos para o teste de aceitação feito por Escala Hedônica foram utilizados para se obter uma média de preferência para cada amostra. Foi feita a análise de variância (ANOVA) de um experimento em blocos casualizados com 7 tratamentos (amostras) e 15 blocos (provadores). Com um nível de significância de 5\% e obtido o $\mathrm{F}$ calculado $(\mathrm{Fc}=69,81)$, compara-se com o $\mathrm{F}$ tabelado $(\mathrm{Ft}=2,85)$ para 7 amostras $\left(\mathrm{n}_{1}=6\right)$ e 15 julgadores $\left(\mathrm{n}_{2}=14\right)$, encontrado na Tabela de valores de $\mathrm{F}$ para o nível de erro $\alpha=5 \%$, segundo número de graus de liberdade de $\mathrm{n}_{1}$ e $\mathrm{n}_{2}$ (NBR 13526, 1995). Como Fc é maior que Ft, existe diferença significativa entre as amostras. Diante disso, faz-se o teste da diferença das médias, o teste de Tukey.

Os resultados foram obtidos utilizando o programa OriginPro 9.0 e com significância de $5 \%$. No resultado gerada, para os pares de amostras com valor igual a ' 1 ', suas médias diferem entre si pelo teste de Tukey. Já os pares seguidos de ' 0 ', não diferem entre si. Sendo assim, as médias das amostras 2 e 7,1 e 6,3 e 5, não apresentam diferenças significativas entre si. Para o perfil de sabor foram plotados gráficos aranha demonstrados na Figura 1, sobrepondo as amostras que não apresentaram diferença pelo teste de Tukey. 
Figura 1 - a. Amostras 2 e 7 (maiores médias) dispostas em gráfico aranha. b. Amostras 1 e 6 (médias intermediarias). c. Amostras 3 e 5 (médias ruins). d. Amostras 4 (pior média).

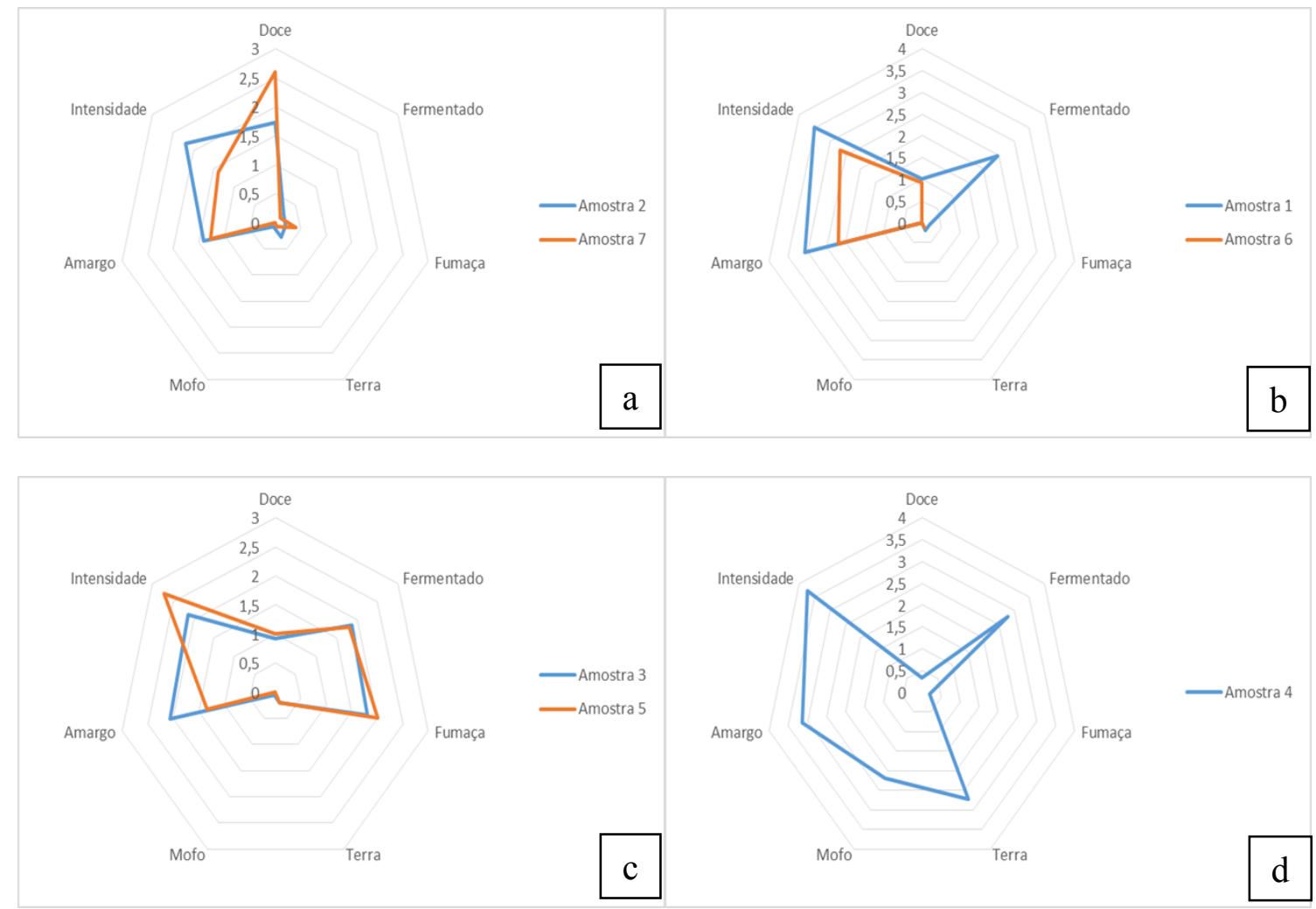

A Figura 1a representa as amostras 2 e 7, que além de terem recebido as maiores médias, apresentam semelhanças para a maioria dos atributos selecionados. Isto indica que estas formas de manejo são as mais recomendáveis, uma vez que o processamento via úmida, como foi feito, diminui o ataque de microrganismos, impedindo a fermentação. Este processamento atribui qualidades como dulçor, intensidade de sabor e amargor, sem sinais significativos de mofo, terra, fumaça e fermentado. Já as amostras 1 e 6 (Figura 1b), que receberam medias intermediárias, não apresentaram valores significativos de mofo, terra ou fumaça. Porém, a amostra 1 apresentou a característica de fermentado, o que provavelmente se deve ao seu processamento por via seca. Ambas apresentaram menor teor de doçura e maior amargor em relação as amostras 2 e 7. Sendo assim, a menor aceitação destas pode ser atribuída a estas características.

Para as amostras 3 e 5 o gráfico aranha na Figura 1c apresenta perfil semelhante para intensidade de sabor, amargor, fumaça, fermentado e doçura, além de não apresentarem sinais significativos de terra e mofo. Em relação às demais, destaca-se o sabor de fumaça como o maior responsável pela baixa média apresentada, seguido pela fermentação. $O$ sabor de fumaça pode ser atribuído a forma de secagem, desse modo, fogo direto não se mostra como uma boa opção de manejo quando se deseja atingir boa qualidade e aceitação pelo mercado. A amostra que apresentou a média mais baixa, e consequentemente a pior aceitação foi a 4 (Figura 1d). A baixa média obtida indica uma má aceitação deste café pelo mercado, isso pode ser atribuído aos altos teores de amargor, mofo, terra e fermentação apresentados. Estas características são obtidas por uma soma de fatores, como a má realização da pré-limpeza, o 


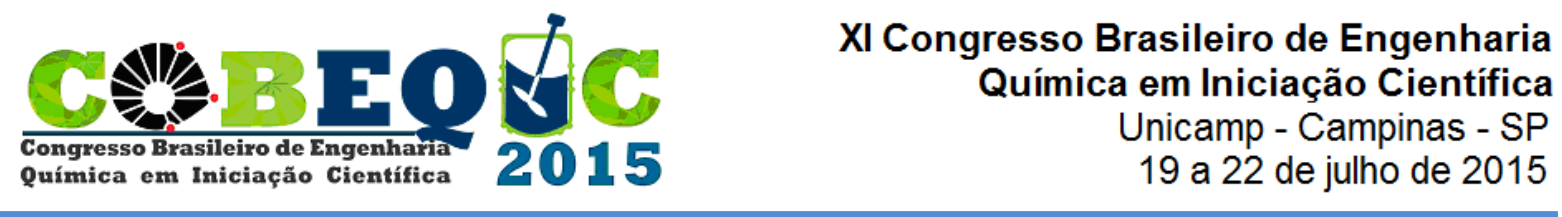

processamento via seca e a forma de secagem. A secagem em terreiro de terra é suscetível a variações climáticas e da temperatura, além da presença de microrganismos, não sendo favorável à qualidade.

\section{CONCLUSÕES}

As amostras utilizadas apresentam diferença significativa entre si para um nível de significância de 5\%. Além disso, as amostras de café Conilon cereja descascado apresentaram a maior aceitação dos consumidores, que ressaltaram suas características de doçura, intensidade de sabor e amargor como preferidas. Não foram caracterizados níveis significantes de fermentação, comprovando a literatura, em que no processamento via úmida se diminui o risco de fermentação. Quanto às formas de secagem, o procedimento realizado em fogo indireto e terreiro coberto se mostraram os mais indicados, não atribuindo características indesejáveis como sabor de terra e de fumaça, percebidos no terreiro de terra e no fogo direto. Sendo aplicada essa metodologia nas lavouras de café Conilon é possível se alcançar uma valorização dos produtos através do aumento na qualidade e diante disso, uma melhora na renda familiar.

\section{REFERÊNCIAS}

AMERINE, M. A.; PANGBORN, R. M.; ROESSER, E. B. Principles of Sensory Evaluation offood. Orlando: Academic Press Inc., 1965.

ASSOCIAÇÃO BRASILEIRA DE NORMAS TÉCNICAS. NBR 12806: Análise sensorial de alimentos e bebidas. Rio de Janeiro, 1993a.

ASSOCIAÇÃO BRASILEIRA DE NORMAS TÉCNICAS. NBR 129955. Teste triangular em análise sensorial de alimento e bebidas. Rio de Janeiro, 1993b.

ASSOCIAÇÃO BRASILEIRA DE NORMAS TÉCNICAS. NBR 13526. Teste de comparação múltipla em análise sensorial dos alimentos e bebidas. Rio de Janeiro, 1995.

BARTHOLO, G. F.; MAGAlhães FILHO, A. A. R.; GUimARÃES, P. T. G.; CHALFOUN, S. M. Cuidados na colheita, no preparo e no armazenamento do café. Informe Agropecuário, v. 14, n. 162, p. 33-44, 1989.

CHAVES, J. B. P.; SPROESSER, R. L. Práticas de laboratório de análise sensorial de alimentos e bebidas. Viçosa: Ed UFV. 1996.

LAWLESS, H. T.; HEYMANN, H. Sensory Evaluation of Food: Principles and Marketing. 2nd Ed., Nova York: Springer, 2010.

MORAIS, S. A. L.; AQUINO, F.J.T.; NASCIMENTO, P.M.; NASCIMENTO, E.A.; CHANG, R. Compostos bioativos e atividade antioxidante do Café Conilon submetido a diferentes graus de torra. Química Nova, Uberlândia, Vol. 32, No. 2, 327-331, 2009. 